\title{
Monocyte and neutrophil to high density lipoprotein cholesterol ratios are elevated in patients with vitamin $D$ deficiency
}

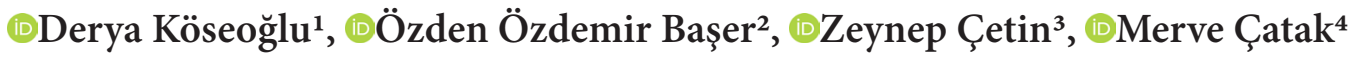 \\ ${ }^{1}$ Hitit University, Faculty of Medicine, Department of Endocrinology and Metabolism, Çorum, Turkey \\ ${ }^{2}$ Yozgat State Hospital, Department of Endocrinology and Metabolism, Yozgat, Turkey \\ ${ }^{3}$ Amasya University, Faculty of Medicine, Department of Endocrinology and Metabolism, Amasya, Turkey \\ ${ }^{4}$ Gaziosmanpaşa University, Faculty of Medicine, Department of Endocrinology and Metabolism,Tokat, Turkey
}

Cite this article as: Köseoğlu D, Özdemir Başer Ö, Çetin Z, Çatlak M. Monocyte and neutrophil to high density lipoprotein cholesterol ratios are elevated in patients with vitamin D deficiency. J Health Sci Med 2022; 5(1): 119-123.

\begin{abstract}
Aim: It is suggested that Vitamin D deficiency may lead to cardiovascular diseases. Monocyte-High density lipoprotein cholesterol (HDL) ratio (MHR) and Neutrophil-HDL ratio (NHR) are markers which may be used as cardiovascular risk factors, which are associated with inflammation. The purpose of this study is to evaluate the MHR and NHR levels in patients with Vitamin D deficiency.

Material and Method: This retrospective study included patients who were tested for Vitamin D levels in our clinic. The subjects were separated into two groups based on their Vitamin D levels and laboratory variables including MHR and NHR were compared.

Results: The subjects with serum $25 \mathrm{OH}$ D level lower and higher than $20 \mathrm{ng} / \mathrm{ml}$ were compared, and MHR and NHR were detected significantly higher in subjects with Vitamin D deficiency (p:0.003 and p<0.001).

Conclusion: Our study indicates for the first time in the literature that MHR and NHR levels increase in Vitamin D deficiency. Our findings suggest that the cardiovascular risk which occurs in Vitamin D deficiency may be associated with the observed increased inflammation. It was detected that MHR and NHR ratios may be used to predict cardiovascular diseases in people with Vitamin D deficiency. Our study also showed that the increased cardiovascular risk which occurs in vitamin D deficiency may be associated with the increased inflammation.
\end{abstract}

Keywords: Atherosclerosis, vitamin D, inflammation, monocyte and neutrophil, high density lipoprotein cholesterol

\section{INTRODUCTION}

Vitamin D3 (cholecalciferol) which is the natural form of vitamin $\mathrm{D}$ originates from the transformation of 7-dehydrocholesterol on the skin through ultraviolet beams (1). The active form of vitamin $\mathrm{D}$ is 1.25 -dihydroxyvitamin $\mathrm{D}(1.25(\mathrm{OH}) 2 \mathrm{D})$ and its well known action is to ensure bone mineralization by increasing the intestinal absorption of calcium (2). 1.25 $(\mathrm{OH}) 2 \mathrm{D}$ acts by binding to vitamin $\mathrm{D}$ receptors (VDR) in many cells of the body including the cardiomyocytes, endothelium, vascular smooth muscle (3). The effects of vitamin $\mathrm{D}$ on the bone metabolism and musculoskeletal system are well-defined (4). The presence of VDR in many tissues led to researches regarding the effects of vitamin $\mathrm{D}$ on other systems apart from bone and musculoskeletal system such as cardiovascular system. Cardiovascular disease (CVD) is the leading cause of mortality and morbidity (5). Studies showed the correlation between Vitamin D deficiency and hypertension, diabetes, metabolic syndrome and immune diseases (4-7). The increased amount of evidences indicate the relationship of vitamin D deficiency with CVD risk factors and CVD mortality (4-8).

Monocytes are the most important cell type for the release of pro-inflammatory and pro-oxidant cytokines at the inflammation site, and they have a primary role in the development of atherosclerosis (9-10). Although the place of neutrophils in atherosclerosis is not clearly exhibited, it was shown that they play a role in the destabilization of atherosclerotic plaques (11). Besides, 
it was detected that the high neutrophil ratio in the peripheral blood is associated with the increase in carotid intima media thickness which is an indicator of atherosclerosis, and it was also higher in patients with intracranial atherosclerotic plaques $(12,13)$. High-density lipoprotein cholesterol (HDL-C) has anti-atherosclerotic activity and it has an inhibiting action on inflammatory and oxidative processes $(8,14)$.

In formerly studies, it was shown that HDL-C inhibits the oxidation of LDL-C, and it protects the endothelial cells against the harmful effects of LDL-C (15). Low HDL-C is an independent and strong indicator for CVD (16). Due to the negative effects of low HDL-C and monocytosis, it is indicated that monocyte/HDL-C ratio (MHR) is a new prognostic indicator in cardiac diseases (17-19). While neutrophile/HDL-C ratio (NHR) is a marker which is studied less, a recent study has indicated that it is a better indicator than MHR in patients with acute myocardial infarction (20).

The relation between vitamin D deficiency and CVD was investigated in various studies, however there is no study indicating the relation of vitamin D level with MHR and NHR ratio. In this study, it is intended to show whether vitamin D level has an effect on MHR and NHR.

\section{MATERIAL AND METHOD}

The study was carried out with the permission of Yozgat Bozok University Clinical Research Ethics Committee (Date: 10.06.2020, Decision No: 2017-KAEK-189 _2020.06.10_01). All procedures were carried out in accordance with the ethical rules and the principles of the Declaration of Helsinki.

\section{Study Population}

The present study is a retrospective multicenter study. The study was conducted on the patients who applied to the outpatient clinics between the 1st of January 2019 and February 2020.

Fifteen thousand patients were screened and the patients who had Vitamin D levels checked were enrolled. The patients who were $<18$ years old; who had Type 1 or Type 2 Diabetes mellitus, prediabetes or those who were on metformin therapy; who were pregnant; who had chronic diseases such as hypertension, chronic renal disease, liver diseases, hypertension, cardiac insufficiency; who had active infection; who had hematological or immunological diseases or malignancies; who had primary hyperparathyroidism; and who were on medications for calcium and lipid metabolism and those using antihypertensive medications were excluded from the study. The demographics and anthropometric data of the patients were recorded. Body mass index (BMI) was calculated as the weight $(\mathrm{kg}) /$ height $(\mathrm{m})^{2}$.

\section{Laboratory Measurements}

Blood samples were obtained from patients in the morning after 12 hours of fasting, for measurement of biochemistry panel including fasting plasma glucose (FPG, 70-100 mg/dl), creatinine (Cre, normal range $0.5-1.1 \mathrm{mg} / \mathrm{dl}$ ), alanine aminotransferase (ALT, normal range 8-38U/L), serum corrected calcium $(\mathrm{Ca}$, normal range $8.5-10.5 \mathrm{mg} / \mathrm{dl}$ ), phosphorus (P, normal range2.5-4.5 $\mathrm{mg} / \mathrm{dl})$, magnesium $(\mathrm{Mg}$, normal range 1.6-2.6 mg/dl), 25-hydroxyvitamin $\mathrm{D}(25 \mathrm{OH}$ vit $\mathrm{D}$, $\mathrm{ng} / \mathrm{ml}$ ), total cholesterol (normal range 0-200 mg/ $\mathrm{dl}$ ), triglyceride (normal range $0-200 \mathrm{mg} / \mathrm{dl}$ ), HDL-C (normal range $45-65 \mathrm{mg} / \mathrm{dl}$ ), LDL-C (normal range $0-130 \mathrm{mg} / \mathrm{dl}$ ), thyroid stimulating hormone (TSH, 0.27$4.2 \mathrm{mU} / \mathrm{L}$ ). Biochemical analyses were determined by standard methods. Corrected calcium was calculated as serum Ca level $(\mathrm{mg} / \mathrm{dl})+0.8 \mathrm{x}(4-$ albumin); nonHDL cholesterol was calculated as total cholesterol-HDL-C.

Samples for complete blood count (CBC) analysis were collected in EDTA anticoagulated Monovette tubes (Sarstedt, Leicester, United Kingdom). Hemoglobin level, Neutrophil count and Monocyte count were obtained from the $\mathrm{CBC}$ analysis. MHR and NHR ratios were determined by dividing the monocyte and neutrophil absolute levels (mm3) to HDL-C level, respectively.

\section{Statistical Analysis}

All Statistical analyses were performed using SPSS version 20.0 (SPSS, Chicago, IL, USA). Normality of the distribution of the continuous variables was evaluated with Kolmogorov-Smirnov test. Continuous variables were compared with independent t-test or Mann-Whitney $\mathrm{U}$ test for normally and non-normally distributed data, respectively. Normally distributed data are described as mean \pm standard deviation, otherwise, as median (minimum-maximum). Chi-square test was used for comparing categorical variables. The mean differences among more than two independent groups were analyzed by one-way ANOVA with Tukey post-hoc test. $\mathrm{p}$ values $<0.05$ were considered statistically significant.

\section{RESULTS}

Patients with insufficient data were excluded from the study and the statistical analysis was conducted with 554 patients. 494 of these patients were female and 60 patients were male; and the average age was $41.07 \pm 13.76$ years. Patients were separated into 2 groups based on $25 \mathrm{OH}$ vit $\mathrm{D}$ level. Patients with lower than $20 \mathrm{ng} / \mathrm{ml} 25 \mathrm{OH}$ vit D level were determined as vitamin D deficiency (n:409) and were compared with patients who had a $25 \mathrm{OH}$ vit D level of 20 and higher (n:145). The comparison of the demographics and several laboratory parameters between two groups is given in Table 1. According to this, it was 
observed that MHR and NHR ratios were statistically significantly higher in the patients with $25 \mathrm{OH}$ vit $\mathrm{D}$ level below 20 (p:0.003 and $\mathrm{p}<0.001$, respectively).

Patients were separated into 4 groups based on the serum $25 \mathrm{OH}$ vit $\mathrm{D}$ level, and the statistical analysis was repeated with One way ANOVA test and a statistically significant difference was observed between the groups in terms of MHR and NHR. Patients with serum $25 \mathrm{OH} \mathrm{D}<10 \mathrm{ng} /$ $\mathrm{ml}$ were defined as group 1 (n:151); patients with serum $25 \mathrm{OH}$ D between $10 \mathrm{ng} / \mathrm{ml}$ and $20 \mathrm{ng} / \mathrm{ml}$ were defined as group 2 (n:258), patients with serum $25 \mathrm{OH} \mathrm{D}$ between $20 \mathrm{ng} / \mathrm{ml}$ and $30 \mathrm{ng} / \mathrm{ml}$ were defined as group 3 (n:108) and patients with serum $25 \mathrm{OH} \mathrm{D}$ more than $30 \mathrm{mg} / \mathrm{ml}$ were defined as group 4 (n:37). There was a statistically significant difference in MHR between the group with serum $25 \mathrm{OH}$ vit D level 20 to $30 \mathrm{ng} / \mathrm{ml}$ and the group with serum $25 \mathrm{OH}$ vit $\mathrm{D}$ level 10 to $20 \mathrm{ng} / \mathrm{ml}$ in the posthoc analysis (p:0.027), but no differences were detected between other groups. When considered in terms of NHR, a statistically significant increase was observed between the group with $25 \mathrm{OH}$ vit D level 10 to $20 \mathrm{ng} /$ $\mathrm{ml}$ and the group with levels 20 to $30 \mathrm{ng} / \mathrm{ml}$ and $30 \mathrm{ng} /$ $\mathrm{ml}$ and above. In the group with $25 \mathrm{OH}$ vit $\mathrm{D}$ level below 10 , NHR was detected significantly higher compared to the group with $25 \mathrm{OH}$ vit D level 20 to $30 \mathrm{ng} / \mathrm{ml}$. One way ANOVA results are given in Table 2.

When a correlation analysis was performed, no correlation at a statistically significant level was detected between $25 \mathrm{OH}$ vit $\mathrm{D}$ level and MHR or NHR.

\section{DISCUSSION}

In this study, it was detected that MHR and NHR were increased in patients with $25 \mathrm{OH}$ vit D level below $20 \mathrm{ng} /$ $\mathrm{ml}$. No additional benefits of increasing the $25 \mathrm{OH}$ vit $\mathrm{D}$ level above 30 could be observed according to MHR and NHR. Our study is the first study investigating the MHR and NHR levels in $25 \mathrm{OH}$ vit D deficiency.

In previous studies vitamin $\mathrm{D}$ deficiency was named as a new cardiovascular risk factor (5). It was previously shown that the parameters such as hsCRP and carotid intima media thickness which are used as cardiovascular risk factors were increased in patients with vitamin $\mathrm{D}$ deficiency $(8,21)$. It was also determined that vitamin $\mathrm{D}$ level is lower in diseases that constitute significant cardiovascular risk such as hypertension, metabolic syndrome and diabetes mellitus (22-24). Besides, it was observed that the cardiovascular events and cardiovascular mortality in people with vitamin D deficiency was increased compared to people with normal vitamin D levels $(25,26)$.

Monocytes play an important role in the first-step in the development of atherosclerosis (27). Monocytes attach to the damaged vascular endothelium, proceed to subepithelial space and transform into mature macrophage. These matured macrophages catch the oxidized LDL molecules and form "foam cells", which leads to the further increase of the inflammation by releasing pro-inflammatory and pro-oxidant cytokines

Table 1. The demographic and laboratory results among the patients with serum $25 \mathrm{OH}$ D levels higher and lower than $20 \mathrm{ng} / \mathrm{mL}$

\begin{tabular}{|c|c|c|c|}
\hline Parameter & Serum $25 \mathrm{OH} D \geq 20 \mathrm{ng} / \mathrm{ml}$ (n: 145$)$ & Serum 25 OH D<20 ng/ml (n: 409) & $\mathbf{p}$ \\
\hline Gender (male/female) & $22 / 123$ & $38 / 371$ & 0.061 \\
\hline Age (years) & $45.6 \pm 14.33$ & $39.46 \pm 13.20$ & $<0.001$ \\
\hline BMI $\left(\mathrm{kg} / \mathrm{m}^{2}\right)$ & $28.60 \pm 5.97$ & $30.96 \pm 7.35$ & $<0.001$ \\
\hline LDL-C (mg/dl) & $125.69 \pm 38.84$ & $123.71 \pm 35.14$ & 0.592 \\
\hline TG (mg/dl) & $118.60 \pm 57.77$ & $125.79 \pm 71.65$ & 0.280 \\
\hline T-CHOL (mg/dl) & $202.86 \pm 47.54$ & $196.90 \pm 42.76$ & 0.190 \\
\hline FPG (mg/dl) & $91.99 \pm 9.39$ & $93.09 \pm 13.52$ & 0.239 \\
\hline Creatinine (mg/dl) & $0.69 \pm 0.14$ & $0.64 \pm 0.13$ & 0.001 \\
\hline $\operatorname{ALT}(\mathrm{U} / \mathrm{L})$ & $20.65 \pm 11.97$ & $20.88 \pm 13.52$ & 0.853 \\
\hline WBC & $6941.10 \pm 1643.88$ & $7336.66 \pm 1639.63$ & 0.014 \\
\hline Hemoglobin & $13.70 \pm 1.24$ & $13.51 \pm 2.17$ & 0.199 \\
\hline Monocyte/HDL-C ratio & $9.80 \pm 3.70$ & $11.03 \pm 5.20$ & 0.003 \\
\hline Neutrophil/HDL-C ratio & $72.42 \pm 30.08$ & $88.04 \pm 35.75$ & $<0.001$ \\
\hline
\end{tabular}

Table 2. The monocyte/ high density lipoprotein cholesterol ratio and neutrophil/ high density lipoprotein cholesterol ratio among the four groups according to One way ANOVA test results

\begin{tabular}{|c|c|c|c|c|}
\hline & Group 1 (n:151) & Group 2 (n:258) & Group 3 (n:108) & Group 4 (n:37) \\
\hline Monocyte/HDL-C ratio* & $10.56 \pm 4.44$ & $11.30 \pm 5.59$ & $9.74 \pm 3.44$ & $9.98 \pm 4.48$ \\
\hline Neutrophil/HDL-C ratio ${ }^{* *}$ & $84.77 \pm 34.93$ & $89.93 \pm 36.15$ & $72.04 \pm 29.01$ & $73.60 \pm 33.59$ \\
\hline
\end{tabular}


(28). In studies, it was shown that HDL-C inhibits the oxidation of LDL-C, and it protects the endothelial cells against the harmful effects of LDL-C, and as a result low $\mathrm{HDL}-\mathrm{C}$ is an independent and strong indicator for CVD $(15,16)$. Due to the negative impacts of low HDL-C and monocytosis, it was shown that MHR is a new prognostic indicator for cardiac diseases (17-19,29).

There are certain numbers of neutrophils on atherosclerotic plaques, and these cause inflammatory response by accumulating on the vein wall (30). Neutrophils are the cells which are in charge in inflammatory response, and in the meantime, when they are activated, they also cause endothelial dysfunction $(31,32)$. When the role of endothelial dysfunction in the development of atherosclerosis is considered, it is believed that neutrophil count is a parameter which may be used in the development of cardiovascular event (13). Besides, in the previous studies, leukocyte count was shown to be associated with diabetes mellitus, obesity and hypertriglyceridemia, and inflammation was shown to contribute to the development of metabolic syndrome $(13,33)$. Such evidences indicate that neutrophils have an effect on atherosclerosis. When the role of high neutrophil and low HDL-C level in the development of atherosclerosis is taken into account, it is considered that NHR may also be used as an atherosclerosis indicator. NHR is not a commonly used parameter in atherosclerosis and cardiovascular diseases, and there are limited data in the literature about this matter. In recent studies, it was detected that NHR was a poor prognostic factor in patients who had myocardium infarction and it increased in patients with metabolic syndrome $(20,34)$.

Although many parameters indicating cardiovascular risk in vitamin D deficiency were previously studied, the relatively new parameters MHR and NHR which may be used as cardiovascular risk indicators were not previously studied in cases of vitamin D deficiency. The purpose of this study is to investigate whether MHR and NHR increased in patients with vitamin D deficiency, and as a result of the statistical analysis, these values were determined significantly high in those with $25 \mathrm{OH}$ vit D level below $20 \mathrm{ng} / \mathrm{ml}$. In light of the data detected in our study, we consider that the increased cardiovascular risk observed in patients with vitamin D deficiency is associated with the increased inflammatory events, and that decreased HDL-C make this more evident. Serum $25 \mathrm{OH}$ vit $\mathrm{D}$ level below $30 \mathrm{ng} / \mathrm{ml}$ is defined as vitamin D insufficiency; below $20 \mathrm{ng} / \mathrm{ml}$ as vitamin D deficiency; and below 10 is defined as severe vitamin D deficiency (35). In our study group, as there were few patients with $25 \mathrm{OH}$ vit D level above $30 \mathrm{ng} / \mathrm{ml}$, the statistical analysis was conducted according to vitamin $\mathrm{D}$ deficiency and those with serum $25 \mathrm{OH}$ vit $\mathrm{D}$ level below and above
$20 \mathrm{ng} / \mathrm{ml}$ were compared. According to this, in patients with vitamin D deficiency, MHR and NHR were detected significantly high. Interestingly, when the serum $25 \mathrm{OH}$ vit $D$ level falls below $10 \mathrm{ng} / \mathrm{ml}$, no significant impairment was observed in MHR and NHR. When these results are evaluated, it is possible to indicate that especially the serum $25 \mathrm{OH}$ vit $\mathrm{D}$ level above $20 \mathrm{ng} / \mathrm{ml}$ contributes to decreased cardiovascular risk. Besides, no additional harm could be shown when $25 \mathrm{OH}$ vit $\mathrm{D}$ level falls below $10 \mathrm{ng} / \mathrm{ml}$.

It is necessary to mention some restrictions regarding the study. Firstly, the retrospective design of the study is a restriction for our results. It would be proper to investigate whether these parameters may be used as a cardiovascular risk marker in time by a prospectively designed study. Despite the sufficient number of total patients, the number of people with $25 \mathrm{OH}$ vit $\mathrm{D}$ level above $30 \mathrm{ng} / \mathrm{ml}$ is small, and this might have prevented us to achieve lower MHR and NHR values in higher 25 $\mathrm{OH}$ vit $\mathrm{D}$ levels, and this may be the reason for failing to obtain a significant result in the correlation analysis. Notwithstanding these restrictions, we achieved valuable data in our study and showed that MHR and NHR ratios were increased in patients with vitamin D deficiency.

\section{CONCLUSION}

As a result, our study has shown for the first time in the literature that MHR and NHR levels were increased in patients with vitamin D deficiency. It is considered that the cardiovascular risk that occurs in vitamin $D$ deficiency may be associated with the increased inflammation and that MHR and NHR ratios may be used to predict cardiovascular diseases in vitamin $\mathrm{D}$ deficiency.

\section{ETHICAL DECLARATIONS}

Ethics Committee Approval: The study was carried out with the permission of Yozgat Bozok University Clinical Researchs Ethics Committee (Date: 10.06.2020, Decision No: 2017-KAEK-189_2020.06.10_01).

Informed Consent: Because the study was designed retrospectively, no written informed consent form was obtained from patients.

Referee Evaluation Process: Externally peer-reviewed.

Conflict of Interest Statement: The authors have no conflicts of interest to declare.

Financial Disclosure: The authors declared that this study has received no financial support.

Author Contributions: All of the authors declare that they have all participated in the design, execution, and analysis of the paper, and that they have approved the final version. 


\section{REFERENCES}

1. Christakos S, Dhawan P, Verstuyf A, Verlinden L, Carmeliet G. Vitamin D: metabolism, molecular mechanism of action, and pleiotropic effects. Physiol Rev 2016; 96: 365-408.

2. Khazai N, Judd SE, Tangpricha V. Calcium and vitamin D: skeletal and extraskeletal health. Curr Rheumatol Rep 2008; 10: 110-7.

3. Wang TJ, Pencina MJ, Booth SL, et al. Vitamin D deficiency and risk of cardiovascular disease. Circulation 2008; 117: 503-11.

4. Wimalawansa SJ. Vitamin D and cardiovascular diseases: Causality. J Steroid Biochem Mol Biol 2018; 175: 29-43.

5. Mandarino NR, Junior F, Salgado JV, Lages JS, Filho NS. Is vitamin $\mathrm{D}$ deficiency a new risk factor for cardiovascular disease? Open Cardiovasc Med J 2015; 9: 40-9.

6. Pacifico L, Anania C, Osborn JF, et al. Low 25(OH)D3 levels are associated with total adiposity, metabolic syndrome, and hypertension in Caucasian children and adolescents. Eur J Endocrinol 2011; 165: 603-11.

7. Tepper S, Shahar DR, Geva D, Ish-Shalom S. Differences in homeostatic model assessment (HOMA) values and insulin levels after vitamin D supplementation in healthy men: a double-blind randomized controlled trial. Diabetes Obes Metab 2016; 18: 6337.

8. Reis JP, von Mühlen D, Michos ED, et al. Serum vitamin $\mathrm{D}$, parathyroid hormone levels and carotid atherosclerosis. Atherosclerosis 2009; 207: 585-90.

9. Ancuta P, Wang J, Gabuzda D. CD16 monocytes produce IL-6, CCL2, and matrix metalloproteinase-9 upon interaction with CX3CL1-expressing endothelial cells. J Leukoc Biol 2006; 80: 1156-64.

10. Weber C, Shantsila E, Hristov M, et al. Role and analysis of monocyte subsets in cardiovascular disease. Joint consensus document of the European Society of Cardiology (ESC) Working Groups "Atherosclerosis \& Vascular Biology" and "Thrombosis." Thromb Haemost 2016; 116: 626-37.

11. Hosokawa T, Kumon Y, Kobayashi T, et al. Neutrophil infiltration and oxidant-production in human atherosclerotic carotid plaques. Histol Histopathol 2011; 26: 1-11.

12.Meng LB, Yu ZM, Guo P, et al. Neutrophils and neutrophillymphocyte ratio: Inflammatory markers associated with intimalmedia thickness of atherosclerosis. Thromb Res 2018; 170: 45-52.

13.Zhang X, Hou XH, Ma YH, et al. Association of peripheral neutrophil count with intracranial atherosclerotic stenosis. BMC Neurology 2020; 20: 65.

14. Murphy AJ. High density lipoprotein: assembly, structure, cargo, and functions. ISRN Physiology 2013; 2013: 20, 20 pages.

15.Li XP, Zhao SP, Zhang XY, Liu L, Gao M, Zhou QC. Protective effect of high density lipoprotein on endothelium-dependent vasodilatation. Int J Cardiol 2000; 73: 231-6.

16. Van den Bogaard B, Holleboom AG, Duivenvoorden R, et al. Patients with low HDL-cholesterol caused by mutations in LCAT have increased arterial stiffness. Atherosclerosis 2012; 225: 481-5.

17. Canpolat U, Aytemir K, Yorgun H, et al. The role of preprocedural monocyte-to-high-density lipoproteinratioinprediction ofatrial fibrillation recurrence after cryoballoon-based catheter ablation. Europace 2015; 17: 1807-15.

18. Cetin EH, Cetin MS, Canpolat U, et al. Monocyte/HDLcholesterol ratio predicts the definite stent thrombosis after primary percutaneous coronary intervention for ST-segment elevation myocardial infarction. Biomark Med 2015; 9: 967-77.

19. Kundi H, Gok M, Kiziltunc E, et al. Relation between monocyte to high-density lipoprotein cholesterol ratio with presence and severity of ssolated coronary artery ectasia. Am J Cardiol 2015; 116: $1685-9$.
20.Huang JB, Chen YS, Ji HY, et al. Neutrophil to high-density lipoprotein ratio has a superior prognostic value in elderly patients with acute myocardial infarction: a comparison study. Lipids Health Dis 2020; 19: 59.

21.Bonakdaran S, Varasteh AR. Correlation between serum 25 hydroxy vitamin D3 and laboratory risk markers of cardiovascular diseases in type 2 diabetic patients. Saudi Med J 2009; 30(4): 50914.

22. Ullah MI, Uwaifo GI, Nicholas WC, Koch CA. Does vitamin d deficiency cause hypertension? Current evidence from clinical studies and potential mechanisms. Int J Endocrinol 2010; 2010: 579640.

23. Lu L, Yu Z, Pan A, et al. Plasma 25-hydroxyvitamin D concentration and metabolic syndrome among middle-aged and elderly Chinese individuals. Diabetes Care 2009; 32: 1278-83.

24.Scragg R, Sowers M, Bell C. Serum 25-hydroxyvitamin D, diabetes, and ethnicity in the $3 \mathrm{rd}$ national health and nutrition examination survey. Diabetes Care 2004; 27: 2813-8.

25. Ginde AA, Scragg R, Schwartz RS, Camargo CA, Jr. Prospective study of serum 25-hydroxyvitamin D level, cardiovascular disease mortality, and all-cause mortality in older U.S. adults. J Am Geriatr Soc 2009; 57: 1595-603.

26. Wang L, Song Y, Manson JE, et al. Circulating 25-hydroxyvitamin $\mathrm{D}$ and risk of cardiovascular disease: A meta-analysis of prospective studies. Circ Cardiovasc Qual Outcomes 2012; 5: 819-29.

27. Ammirati E, Moroni F, Magnoni M, et al. Circulating CD14+ and CD14 high CD16-classical monocytes are reduced in patients with signs of plaque neovascularization in the carotid artery. Atherosclerosis 2016; 255: 171-8.

28. Ghattas A, Griffiths HR, Devitt A, Lip GY, Shantsila E. Monocytes in coronary artery disease and atherosclerosis: where are we now? J Am Coll Cardiol 2013; 62: 1541-51.

29. Villanueva DLE, Tiongson MD, Ramos JD, Llanes EJ. Monocyte to High-Density Lipoprotein Ratio (MHR) as a predictor of mortality and Major Adverse Cardiovascular Events (MACE) among ST Elevation Myocardial Infarction (STEMI) patients undergoing primary percutaneous coronary intervention: a metaanalysis. Lipids Health Dis 2020; 19: 55.

30.Qi H, Yang S, Zhang L. Neutrophil extracellular traps and endothelial dysfunction in atherosclerosis and thrombosis. Front Immunol 2017; 8: 928.

31.Davignon J, Ganz P. Role of endothelial dysfunction in atherosclerosis. Circulation 2004; 109: III27-32.

32. Chung JW, Oh MJ, Cho YH, et al. Distinct roles of endothelial dysfunction and inflammation in intracranial atherosclerotic stroke. Eur Neurol 2017; 77: 211-9.

33. Stewart RA, White HD, Kirby AC, et al. White blood cell count predicts reduction in coronary heart disease mortality with pravastatin. Circulation. 2005; 111: 1756-62.

34. Tong $\mathrm{C}$, Chen $\mathrm{H}$, Xiao $\mathrm{H}$, et al. Comparison of the value of neutrophil to high-density lipoprotein cholesterol ratio and lymphocyte to high-density lipoprotein cholesterol ratio for predicting metabolic syndrome among a population in the Southern Coast of China. Diabetes, Metabolic Syndrome and Obesity: Targets and Therapy 2020; 13: 597-605.

35. Holick MF. Vitamin D deficiency. N Engl J Med 2007; 357: 266-81. 